\title{
PRÁTICAS PEDAGÓGICAS ADOTADAS POR DOCENTES DO ENSINO MÉDIO PARA REDUÇÃO DA EVASÃO ESCOLAR
}

\author{
Gecilane Ferreira \\ Eliane Ribeiro \\ Universidade Federal do Tocantins - UFT. Araguaína, Brasil \\ Lucimar Rodrigues Vieira Curvo \\ Sonia Biaggi Alves de Alencar \\ Aguinel Messias de Lima \\ Alexander Stein de Luca \\ Rodolfo José de Campos Curvo \\ Instituto Federal de Educação, Ciência e Tecnologia de Mato Grosso - IFMT. Cuiabá, \\ Brasil. \\ Patrícia Maria Martins Napólis \\ Universidade Federal do Piauí - UFPI. Teresina, Brasil
}

\begin{abstract}
Resumo. Hipóteses levantadas por profissionais que atuam em uma instituição de Ensino Médio de Araguaína, em Tocantins - Brasil, apontam que o nível da qualidade do ensino está inversamente relacionado ao abandono escolar e que a inflexibilidade nas metodologias adotadas em sala de aula contribui para ampliar a evasão. Tendo o referido debate como condição motivadora, esta pesquisa objetiva analisar a percepção da coordenação pedagógica em relação às ações a serem adotadas pelos docentes no sentido de minimizar a evasão, avaliando também as práticas implementadas, visando destacar as consideradas exitosas. $\mathrm{O}$ estudo envolveu a coordenadora pedagógica e três docentes da unidade escolar. Embora os documentos da escola indiquem a teoria construtivista como uma das opções pedagógicas, os resultados demonstram que as metodologias empregadas pelos docentes ainda acentuam o modelo tradicional, dificultando a articulação entre teoria e prática e a contextualização dos conteúdos curriculares. Contudo, foram identificadas práticas exitosas que, ao serem compartilhadas e valorizadas, podem impulsionar novas alternativas, já que as mesmas têm contribuído para ressignificação dos processos de ensino e de aprendizagem.
\end{abstract}

Palavras-chave: Prática pedagógica, metodologias de ensino, evasão escolar.

\section{PEDAGOGICAL METHODS ADOPTED BY HIGH SCHOOL TEACHERS TO REDUCE SCHOOL EVASION}

\begin{abstract}
Professionals from a high school in Araguaína (in the state of Tocantins, Brazil) have raised a hypothesis that indicates that the level of quality of teaching is related to school evasion. The inflexibility of classroom methodologies and approaches to teaching has fostered evasion rates. Motivated by the aforementioned debate, this piece of research aims at analyzing the perception of teachers and pedagogical coordinators of measures taken in order to minimize school evasion with an emphasis on those measures considered to have been successful. With a qualitative approach to the subject, this exploratory piece of research has looked at the pedagogical coordinator and three teachers from a selected high school. Even though the school documents mention the constructivist theory as a pedagogical option, results revealed
\end{abstract}


that the methods employed by teachers still prioritize the traditional model, thus, hindering the articulation between theory and practice and the contextualization of curricular content. However, successful methods were also identified that have contributed to a renewal of the processes of teaching and learning and which if shared, and valued, may generate new alternatives.

Keywords: Pedagogical practices. teaching methodologies. school evasion.

\title{
PRÁCTICAS PEDAGÓGICAS ADOPTADAS POR DOCENTES DE LA ENSEÑANZA MEDIA PARA LA REDUCCIÓN DE LA DESERCIÓN ESCOLAR
}

\begin{abstract}
Resumen. Las hipótesis planteadas por los profesionales que actúan en una institución de Enseñanza Media de Araguaína, en el estado de Tocantins - Brasil, señalan que el nivel de la calidad de la enseñanza está relacionado al abandono escolar, y que, además, la inflexibilidad en las metodologías adoptadas en el aula contribuye para aumentar la deserción. Motivados por el anterior debate, esta investigación tiene por objetivo analizar la percepción de la coordinación pedagógica y de los docentes en relación a acciones dirigidas a minimizar la deserción escolar, con vistas a destacar las que se consideren exitosas. Este estudio, el cual se constituye como exploratorio y adopta un enfoque cualitativo, tuvo como participantes a la coordinadora pedagógica y a tres docentes de una unidad escolar. A pesar de que los documentos de la escuela apunten a que la teoría constructivista es una opción pedagógica, los resultados demuestran que las metodologías empleadas por los docentes todavía acentúan el modelo tradicional, lo que a la postre dificulta la articulación entre teoría y práctica, y la contextualización de los contenidos curriculares. Sin embargo, se identificaron prácticas exitosas que, cuando son compartidas y valoradas, pueden impulsar nuevas alternativas, pues han contribuido para la resignificación de los procesos de enseñanza y aprendizaje.
\end{abstract}

Palabras clave: Práctica pedagógica, metodologías de enseñanza, deserción escolar.

\section{Introdução}

A evasão escolar tem sido o foco de várias pesquisas na área educacional brasileira (Bahia, 2001, Lamers, Santos e Toassi, 2017, Pedralli e Cerutti-Rizzatti, 2013) e vem sendo demonstrada como um forte indicativo dos problemas vivenciados pelas instituições de ensino. Por atingir as diferentes etapas do ensino, o fenômeno reduz as matrículas no decorrer do processo formativo e minimiza as possibilidades de ingresso no Ensino Superior.

Vários são os conceitos atribuídos à evasão escolar. Entre eles, destaca-se a definição da Comissão Especial de Estudos sobre a Evasão, vinculada ao Ministério da Educação - MEC, que a considera a saída definitiva do estudante de seu curso de origem, sem concluí-lo. Além disso, define a evasão como sendo também a diferença entre ingressantes e concluintes, após uma geração completa (Brasil, 1996).

Em sua estruturação, a evasão constitui-se em um fenômeno que implica dois processos: a) a evasão anual média: alunos matriculados em um sistema de ensino, em uma instituição de ensino ou em um curso que, não tendo se formado, também não se matricularam no ano seguinte (ou no semestre seguinte); b) o número de alunos que, tendo ingressado em determinado curso, instituição ou sistema de ensino, não obteve o diploma 
ao final de um certo número de anos. É o complemento do que se chama índice de titulação (Silva Filho e outros, 2007).

Lüscher e Dore (2011), por sua vez, afirmam que a evasão tem sido associada: à saída do aluno da instituição; à saída do aluno do sistema de ensino; à não conclusão de um determinado nível de ensino; e, também, ao abandono da escola e posterior retorno. Refere-se, ainda, àqueles indivíduos que nunca ingressaram em um determinado nível de ensino.

Quanto aos fatores que contribuem para a evasão, Lüscher e Dore (2011) destacam a composição do corpo discente, os recursos escolares, as características estruturais da escola, bem como os processos e as práticas pedagógicos. Cada um desses fatores desdobra-se em muitos outros e, no seu conjunto, compõem o quadro que pode favorecer a evasão ou a permanência do estudante. Já Castilho e Lopes (1996), fazem referência ao comprometimento do corpo docente, sendo que convergem quanto à necessidade de observar as condições diversas dos próprios estudantes.

Constitui-se, portanto, em um fenômeno cujas causas são diversificadas e que, para Silva Filho e outros (2007, p. 642), afeta o setor público, em função dos investimentos sem o devido retorno, e o setor privado, por reduzir suas receitas. Por isso, em ambos os casos “... a evasão é uma fonte de ociosidade de professores, funcionários, equipamentos e espaço físico."

Diante da complexidade do próprio fenômeno e de suas possíveis causas e consequências, destacamos aspectos a serem considerados se o propósito for ampliar a permanência e reduzir a evasão. São eles: a exclusão educacional, a metodologia utilizada em sala de aula, a formação docente e a relação entre docente e estudante.

Em relação à exclusão educacional, Enguita e outros (2010) lembram que a qualidade do sistema educacional de um país é, além de um indicador dos níveis de desenvolvimento e bem-estar social, um indicador de como será o futuro daquela nação. Estudos como o de Lucas (1998), Barro (1991), Mankiw, Romer e Weil (1992) associam maiores níveis educacionais a um maior crescimento econômico, assim como os trabalhos de Card (1999) e Murnane e outros (1995) afirmam que o impacto dos níveis mais elevados de formação na renda futura do indivíduo é positivo. Dessa forma, observamos que a qualidade do ensino influencia na realidade dos jovens e adultos, contribuindo para condições de vida distintas.

Enquanto a Constituição Federal do Brasil, em seu art. 205, determina que a educação é um direito de todos e dever do Estado e da família, assim como estabelece os princípios de igualdade de condições para acesso e permanência na escola (art. 206, inciso I) (Brasil, 1988) e a Lei de Diretrizes e Bases da Educação Nacional n ${ }^{\circ}$ 9.394, ratifica essa condição (Brasil, 1996), Giddens (2005) afirma que, durante séculos, a educação formal esteve disponível apenas para uma minoria que dispunha de tempo e condições financeiras para dedicar-se aos estudos. Apesar dos avanços das últimas décadas, acesso e permanência não são ainda direitos ao alcance de toda a população brasileira.

Diante do contingente significativo de estudantes que se evadem, além das responsabilidades governamentais, compete ao docente fazer a análise da concepção pedagógica que norteia sua prática em sala de aula, da metodologia selecionada e das formas de se autoavaliar e de avaliar a aprendizagem dos estudantes. Outrossim, deve, ainda, analisar as especificidades dos estudantes no sentido de oferecer condições para que se apropriem dos conteúdos curriculares. 
Quanto à metodologia, especificamente, existe um consenso no sentido de ressaltar que o modelo escolar, ainda priorizado na realidade atual, está ultrapassado, deixando de ser interessante para os estudantes (Lara, 2003). Para Souza e Reinert (2010) os processos de ensino e de aprendizagem precisam promover o papel ativo do estudante. Da mesma forma, destaca-se a importância de incentivar a formação de estudantes interativos, reflexivos, propositivos e estimulados quanto ao sentido de pertencimento.

Araújo (2006) defende que a metodologia aplicada pelo docente não pode ser pensada sem a prática e sem a contextualização. Além disso, destaca-se que a escolha da concepção e sua articulação com a metodologia, bem como a forma de avaliar é que vão constituindo diferentes perfis de docentes.

Entre esses perfis, Libâneo (2001) ressalta os mais tradicionais, que se limitam a transmitir o conteúdo definido nos livros didáticos. Suas aulas são sempre iguais, o método de ensino é quase o mesmo para todas as disciplinas, independentemente da idade e das características individuais e sociais dos estudantes; ressalta, também, os atualizados que variam seus métodos de ensino, se preocupam com as diferenças individuais e socioculturais dos estudantes, costumam fazer trabalhos diversificados e estimulam o diálogo.

Apesar das especificidades, Libâneo (2001) alerta que, ainda assim, uma parte significativa de docentes continua presa a uma didática tradicional de ensino. Dessa forma, na hora de cobrar os resultados de processos de aprendizagem, continua acentuando a memorização e a repetição de fórmulas e definições, o que reduz as possibilidades para que os estudantes acessem, se apropriem, construam e difundam conhecimentos de forma consciente e autônoma. Existe, assim, uma necessidade de reconstruir identidades docentes para trabalhar com processos de inovação (Nóvoa, 1992).

Nesse sentido, Perrenoud (2000) lembra que a sociedade está em constante mutação, requisitando uma formação científica que seja analítica e crítica. Para o autor, esses dois aspectos de formação são essenciais para viabilizar a qualidade do ensino e, consequentemente, da formação dos egressos do sistema escolar.

O autor também salienta que não é possível formar professores sem fazer escolhas ideológicas e que isso depende do modelo de sociedade e de ser humano que defendemos. Outrossim, quando um professor define a metodologia utilizada em sala de aula, está também indicando a sua forma de conceber o mundo.

Diante dessa constatação, Perronoud (2000) destaca que as finalidades de um sistema educacional e as competências não podem estar dissociadas. Então, é necessário definir onde se pretende chegar, o que um professor deve saber, não para ensinar, mas para fazer aprender; não para transmitir o saber, mas para construir competências e uma identidade, uma relação com o mundo e com o saber.

É nesse contexto que emerge a importância da formação continuada de docentes, que ganhou destaque internacional entre os anos 1980 e 1990, em função de vários fatores, entre os quais, a insatisfação e a preocupação da sociedade com a qualidade do ensino. Destaca-se, diante desse contexto, o estudo da Fundação Victor Civita (2011), cujo diagnóstico apontou para o baixo desempenho dos estudantes, atribuído, em sua maioria, aos docentes e a sua formação e também ao pouco suporte proporcionado pelo sistema escolar.

A pesquisa aborda a necessidade da formação continuada em razão da formação inicial apresentar muitas limitações e, em muitos casos, ser de extrema precariedade. 
Então, a formação continuada vem suprir as inadequações deixadas pela formação inicial, que repercutem fortemente no trabalho docente. A formação continuada também tem sua relevância em função da dinamicidade do campo educacional e de toda sua complexidade, condições que requisitam educadores que lidem constantemente com novos conhecimentos a respeito dos processos de ensino e de aprendizagem.

Apesar da crescente consciência do papel renovador da formação continuada, existem desafios apontados pela pesquisa realizada pela Fundação Victor Civita, em 2011, os quais incorporam a disponibilidade docente e a aproximação dos processos formativos com a realidade vivenciada pelos profissionais. Nesse sentido, salienta a importância da participação de docentes e gestores na elaboração de projetos de formação continuada (Guskey e Huberman, 1995). Independentemente de seu planejamento, a formação continuada é central para o desenvolvimento pessoal e profissional dos educadores; é uma escolha necessária para que se possa dar sentido e valor à atividade docente (Fundação Victor Civita e Hargreaves, 1995).

O processo de formação do docente é contínuo, inicia-se antes mesmo do curso de graduação, nas interações com os autores que fizeram e fazem parte de sua formação preliminar. E, nesse processo, sofrem influência dos acontecimentos históricos, políticos e culturais, possibilitando novos modos de pensar e diferentes maneiras de agir perante a realidade de inserção profissional (Parsserine, 2007, p. 18). Mas ocorre também no Ensino Superior e depois de seu término, sendo, portanto, um processo permanente.

Ao discutir a formação continuada, Torrance (2014) referência a influência que programas de pós-graduação podem ter, para além da participação individual, na promoção da capacidade de reflexão crítica e na transformação das práticas dos docentes. Dessa forma, acentua-se a necessidade de articular Ensino Superior e Educação Básica, no sentido de que ambos possam valorizar e potencializar as iniciativas inovadoras, ressignificando, também, as que apresentam tal necessidade.

No século XVII, a necessidade da formação dos docentes já era preconizada por Comênio. No entanto, no Brasil, foi somente no século XIX que a problemática 'formação de professores' se configurou (Saviani, 2009). A partir de então, foram sendo configurados dois modelos de formação docente:

- Modelo dos conteúdos culturais e cognitivos: voltado para a formação do professor vinculada à cultura no geral e ao domínio específico dos conteúdos da área de conhecimento correspondente à disciplina que irá abordar;

- Modelo pedagógico/didático: contrapondo-se ao anterior, considera que a formação do professor propriamente dita só se completa com o efetivo preparo pedagógico/didático.

Ao perfilar sua condição a partir da realidade pessoal e formativa, o docente estabelece formas diferenciadas de se relacionar com os estudantes. Essa relação transforma-se em um dos aspectos de relevância no processo pedagógico, tornando-se impossível desvincular a realidade escolar deste fator.

Os docentes que se relacionam bem com os seus alunos, estimulam a permanência, pois a confiança e a valorização não só ampliam o sentido de pertencimento, mas também estimulam a prática do ensino contextualizado, pois a amizade ou a confiança que existe entre eles se transforma em uma via de mão dupla, pois ambos (professores e alunos) podem ensinar e aprender através de suas experiências. Alunos, professores, diretores, coordenadores, bibliotecários, merendeiros, familiares...enfim, todos na escola têm 
emoções e estabelecem vínculos - com os conhecimentos e com as pessoas. Portanto, reinserir as habilidades socioemocionais na proposta pedagógica das escolas é considerar os seres que comparecem à escola em sua integralidade (ABED, 2016).

Abed (2016, p. 11) também registra que "A mudança nas concepções de ser humano, de ensino, de aprendizagem e de conhecimento realoca os papéis e as responsabilidades dos principais protagonistas da escola: o professor e o aluno." Nessa direção, a organização aponta que "... As teorias baseadas nas abordagens interacionistas coadunam com o paradigma aqui discutido, pois concebem o humano como resultante de um processo contínuo de construção, desconstrução e reconstrução nas e pelas interações sociais. A todo o momento, ensinante e aprendente estão se encontrando e se transformando ao olharem para os objetos do conhecimento."

Gadotti (1999, p. 2) lembra que, ao dinamizar o diálogo, “... o educador não pode colocar-se na posição ingênua de quem se pretende detentor de todo o saber; deve, antes, colocar-se na posição humilde de quem sabe que não sabe tudo,...”. Essa perspectiva se contrapõe à do docente que prioriza uma rotineira transmissão de conhecimentos fragmentados e descontextualizados.

O desempenho docente e as perspectivas sobre educação impõem uma lógica ligada aos conceitos de virtude, caráter e tomadas de decisão nas práticas de ensino. Ou seja, explorar o lugar da virtude, da sabedoria prática e do caráter como forma de um entendimento satisfatório de um ensino com qualidade (Cruz e outros, 2015, p. 147).

Como o ensino não pode e não deve ser algo estático e unidirecional, devemos nos lembrar de que a sala de aula não é apenas um lugar de transmitir conteúdo teórico; é também, local de aprendizado de valores e comportamentos, de aquisição de mentalidade científica lógica e participativa, que poderá possibilitar ao discente, interpretar a sociedade e a natureza de modo benéfico (Ceratti, 2014).

Na conclusão de Bullough (2015), os discentes necessitam de docentes atenciosos, competentes e que invistam na profissão, tornando-se importantes no seu desenvolvimento. Todas essas demandas tornam o processo de ensino exigente em termos emocionais e, como tal, podem explicar a exaustão apresentada por alguns professores (Tuxford e Bradley, 2014).

Percebe-se, então, a veracidade das convicções de Wang, Hall e Rahimi, (2015) quando indicam que os docentes que apresentam forte crença na sua capacidade de envolver os estudantes na aprendizagem, são os que reportam maior satisfação no trabalho e menos burnout (exaustão emocional e realização pessoal) e também sintomas de doença menos frequentes. Nesse ínterim, dinamizam a prática com metodologias e estratégias didáticas que favorecem a inclusão e ampliam as possibilidades de permanência.

Reside nessa condição, a justificativa e a importância de abordar a prática pedagógica como objeto de pesquisa. Nesse ínterim, esta pesquisa tem por objetivo não só analisar as metodologias desejadas pela escola, bem como a realidade das práticas de sala de aula utilizadas por alguns docentes, procurando identificar as alternativas exitosas, especialmente as que favoreçam e promovam a aprendizagem do aluno, estimulando sua permanência. 
Método

Para o alcance do objetivo proposto, optou-se pela pesquisa exploratória, apoiada pela abordagem qualitativa. A alternativa ofereceu condições para levantar a percepção dos sujeitos da pesquisa sobre as metodologias desejadas pela escola e, também, a realidade das práticas de sala de aula utilizadas por alguns docentes, destacando as que vêm contribuindo para ressignificar os processos de ensino e de aprendizagem.

Os dados foram coletados por meio de uma entrevista semiestruturada que envolveu a pedagoga da escola - atualmente responsável pela coordenação - e três docentes. Em função dos compromissos éticos, identificamos os sujeitos da pesquisa como 'Profissional' $(\mathrm{P})$, denominação seguida por um algarismo indicando a ordem numérica.

O roteiro de entrevista foi composto por oito questões, incluindo-se, no decorrer da coleta, dados que transcendiam as mesmas, em função das considerações relevantes que foram surgindo. Os dados coletados foram analisados por meio da confrontação com a revisão bibliográfica.

\section{Resultados e discussão}

De acordo com o P2, os alunos da escola pesquisada costumam se ausentar de parte das aulas, alegando que não se identificam com docentes de determinadas disciplinas. Segundo este profissional “... os problemas maiores como indisciplina, atos de vandalismo e o desrespeito contra os professores, começaram quando uma mulher assumiu a direção, pois os discentes consideram mulheres incapazes e inferiores aos homens. " Essa visão confirma o preconceito em relação à posição da mulher. Além disso, entre os problemas, constam os altos índices de reprovação que a escola teve nos últimos anos.

Segundo Silva e Abud (2016 p. 87) "A disciplina é considerada um fator indispensável quando se trata das relações presentes em qualquer instituição, seja ela escolar, militar, religiosa, entre outras. No entanto, o próprio termo disciplina admite várias concepções.

Ferreira (2009) indica que pode significar um regime de ordem imposto ou livremente consentido. Ordem que convém ao funcionamento regular de uma organização, bem como a relações de subordinação do aluno ao mestre ou ao instrutor.

A disciplina pode ser entendida não só de forma pejorativa e cerceadora (ordem imposta, submissão), mas também de forma construtiva e otimista (livremente consentida, observância de preceitos e normas). Isso significa que a maneira como o indivíduo conceber esse termo será um fator determinante para orientar, no caso do docente, suas ações profissionais e, no caso do aluno, sua conduta na instituição de ensino. Daí podermos encontrar abrigadas, no mesmo termo, atitudes notadamente autoritárias ou iniciativas de natureza democrática e consensual, que visem garantir a 'boa convivência’ em sala de aula.

Em meio a essas questões, o P1 alerta que a escola tem tomado atitudes para diminuir a evasão, como a criação de um conselho, formado por professores, pais e alunos. Embora o foco da pesquisa seja o Ensino Médio, etapa em que parte substancial dos estudantes atingiu a maioridade, é essencial ressaltar que, independente da idade, a participação dos pais é sempre importante, pois a construção de valores e saberes é, prioritariamente, coletiva. $\mathrm{O}$ conselho tem encontros definidos para cada fim de bimestre, 
com o objetivo de discutir o desempenho, o comportamento e as faltas consecutivas dos alunos.

Outra proposta em questão é a criação de programas que auxiliem os estudantes a compreender as disciplinas em que possuem dificuldades, bem como estimulem os docentes a inovar no sentido de superar as aulas tradicionais. Para as aulas diferenciadas, o projeto pretende contar com o apoio de uma psicóloga, pois muitos dos comportamentos agressivos e o déficit de atenção são reflexo de algum trauma vivenciado no meio em que estão inseridos. Essa proposta ainda está em discussão, mas é de extrema relevância para a transformação do contexto escolar e para a redução da evasão, conforme indicado pela P1.

Partindo deste pressuposto, buscamos identificar quais as metodologias que têm norteado o trabalho em sala de aula. Segundo o P1, a escola utiliza como base para suas ações metodológicas a teoria construtivista e o ensino tradicional. Ao persistir no aprofundamento da primeira concepção, visa contribuir para a formação de estudantes críticos, formadores do seu próprio conhecimento.

Em uma sala de aula tradicional o professor é a autoridade máxima e o detentor do conhecimento, enquanto que na construtivista, o professor atua como facilitador, ajudando os alunos na busca pelo conhecimento. Diante das dificuldades que a escola apresenta em gerenciar o comportamento dos estudantes, se faz necessária a autoridade do professor, mas de forma que desperte o interesse pela busca do conhecimento e possibilite uma convivência mais harmoniosa.

De acordo com a P1, as maiores dificuldades enfrentadas pela escola são: a falta de segurança, a violência, as disparidades socioeconômicas e culturais, bem como a falta da participação dos pais. Devido a esses fatores, muitos estudantes deixam de frequentar as aulas, ocasionando a elevação dos índices de evasão. Uma vez que os estudantes não buscam a escola como meio para apropriação de conhecimentos, mas como distração, fazer novas amizades, garantir uma renda mensal (bolsa família), alimentação e também acesso gratuito à internet, tem-se mais um reflexo que é a ampliação dos índices de reprovação, principalmente nas áreas de Exatas, Ciências Naturais e Inglês.

Para contornar essas problemáticas, a escola busca metodologias alternativas. No entanto, busca primeiramente, capacitar os docentes, por meio de formação continuada. A partir das formações, espera-se que possam desenvolver alternativas que atendam às necessidades das turmas envolvidas nos processos de ensino e de aprendizagem.

Quando questionada sobre o comportamento dos docentes diante das situaçõesproblema vivenciadas pela escola, o P1 ressaltou que, mesmo sendo afetados por esses fatores, os mesmos precisam demonstrar domínio e segurança. "Onde há disciplina não há indisciplina; o educador precisa ter olhos de águia e enxergar longe e, mesmo diante das dificuldades apresentadas, seu dever é buscar novas alternativas para sanar ou minimizar os problemas. "

Para facilitar o trabalho, a escola tem o apoio de psicólogo para atender, principalmente, os docentes. Entre suas tarefas, solicita-se ao profissional que auxilie os docentes na mediação de conflitos e no desenvolvimento de estratégias para o atendimento de estudantes que requisitam uma atenção mais personalizada.

Procurando observar a relação entre a visão do P1 e o que ocorre na prática em sala de aula, os demais profissionais entrevistados foram estimulados a contextualizar as metodologias praticadas dentro da sala de aula e também a identificar a existência de alguma prática exitosa. 
O P2 ressalta que usa de forma articulada o ouvir, o pensar e o agir. Dessa maneira, procura compreender a realidade do estudante para intervir no seu comportamento e aprendizado. Além disso, destaca que, baseado nas proposições de Vygotsky, a escola desenvolve aulas extracurriculares que estimulam os estudantes no seu desenvolvimento, além de ações de reconhecimento dos que se comprometem com os estudos.

Em relação ao P3, foi destacado pelo mesmo que sua metodologia é muito teórica e conteudista, sendo amparado, especialmente, pelo livro didático disponibilizado pela escola. Quando questionado sobre os motivos que o levam a utilizar essa metodologia, justificou que o fator principal é a falta de tempo, tanto em planejar aulas, como em relação ao tempo em sala de aula que é apenas de uma hora semanal.

O professor $\mathrm{P} 4$, além de dominar o conteúdo da área de sua formação, se sente à vontade para lecionar outro componente da matriz curricular. Sua metodologia é rotativa, sendo diversificada de acordo as necessidades dos seus alunos. Para abordar o conteúdo, busca utilizar recursos tecnológicos, bem como dinâmicas alternativas em sala de aula. Ainda assim, na maior parte do tempo utiliza o pincel e o quadro, principalmente quando as disciplinas envolvem muitos cálculos matemáticos. No entanto, não há experimentações em suas disciplinas, não só por falta de tempo, mas também de materiais laboratoriais.

O P3 também se limita ao quadro e ao pincel e também não utiliza aulas experimentais. No entanto, preocupado em manter a atenção dos estudantes, procura ser um docente agradável, utilizando estratégias que os deixem mais à vontade, sem, contudo, levá-los a perder o respeito pelos colegas e pelo próprio docente.

Essa análise efetuada sobre as abordagens metodológicas utilizadas pelos docentes permitiu-nos constatar que a persistência do método tradicional dificulta práticas interacionistas. A discussão que surge a partir das propostas dos Parâmetros Curriculares Nacionais (PCN) é que o ensino seja voltado à contextualização (Brasil, 2000). Ou seja, que ao abordar determinado conteúdo, o docente inicie a partir dos conhecimentos prévios dos alunos, vinculando as aulas às vivências e percepções, evidenciando suas aplicações práticas.

Essa mesma proposta curricular apresentada pelos PCN passou a influenciar a formação inicial e continuada dos professores e sugere uma reorientação curricular, indicando também o tipo de formação que se pretende para os docentes, quanto à produção de livros e à elaboração de outros materiais didáticos. Essas opções poderiam contribuir para a inovação, evitando a rotina da metodologia tradicional.

Embora a proposta da escola se enquadre dentro do que é sugerido pelo PCN, observa-se que precisa avançar. É preciso encontrar mecanismos que estimulem os docentes a transformar suas práticas, entrelaçando o conteúdo com a realidade dos estudantes, além de ampliar a interação entre teoria e prática. Nesse sentido, Nóvoa (1999) alerta que a profissionalização dos professores depende da possibilidade de construir um saber pedagógico que não seja puramente instrumental, focado nos conteúdos, mas também preocupado em como intermediar tais saberes.

Para compreender melhor os fatores que os levam a deixar de lado essa contextualização e experimentações, Axt (2001) destaca: a falta de tempo para planejamento; a carga horária extensa; o trabalho isolado e individualizado; e, ainda, a falta de familiaridade com atividades experimentais simples, que possam ser realizadas em uma sala de aula comum com materiais de fácil obtenção. A maior parte dos professores não realiza atividades experimentais porque acredita que são muito 
trabalhosas, exigem tempo excessivo, espaço e materiais específicos. Isso faz com que os docentes não se sintam seguros quanto à forma de incorporar este recurso na dinâmica de suas aulas.

Assim como a profissional responsável pela coordenação pedagógica, os docentes entrevistados destacaram que a insegurança em sala de aula, bem como a falta de compromisso dos estudantes dificultam e, às vezes, até os inibem de adotarem uma metodologia diferente daquela a que já estão habituados. E é mais agravante nas turmas do noturno. "A sensação é que estou lecionando para a parede", essa foi uma das falas de um dos entrevistados.

Como meio de despertar o interesse dos estudantes, a coordenação mencionou que utiliza a premiação como fonte de motivacional. Para os docentes, a premiação não tem um efeito muito amplo, em função da demora na entrega dos prêmios que são de responsabilidade do Estado.

Os melhores destacados de algumas escolas da Rede Estadual, especificamente do Ensino Médio, foram contemplados com um tablet. No entanto, a entrega pelo governo ocorreu muito tempo após, desestimulando os docentes e os próprios estudantes.

Acrescentando ao que já foi exposto, os entrevistados destacaram que a interferência do Estado no processo de tomada de decisões da escola, tem afetado sua autonomia, contribuindo para o desenvolvimento fragmentado dos processos de ensino e de aprendizagem. Em contrapartida, Saviani (2000) alerta que o professor tem como missão transformar a sociedade, pois é o personagem principal da educação, enquanto Veiga (2000) acrescenta que em sala de aula o professor deve estar presente, inteiro, motivado, bem como formado e consciente. Já Alves (2007) complementa que nenhuma escola, nenhum sistema educacional será melhor do que a qualidade e a habilidade do docente. Sua prática pedagógica, porém, dependerá de três fatores: qualidade básica, habilidade pessoal e preparo teórico/prático.

Nesse sentido, apesar das dificuldades abordadas e das aulas ainda bastante tradicionais, foi possível observar que alguns docentes conseguem dinamizar boas intervenções metodológicas nos processos de ensino e de aprendizagem. Uma das práticas consideradas exitosas, utilizada pelo P3, envolve os conteúdos da disciplina física, força, resistência e velocidade. A dinâmica consiste no uso da brincadeira "Cabo de Guerra", cuja prática foi considerada uma modalidade Olímpica nos anos de 1900 a 1920. Contextualizando o que foi dito por este professor sobre a falta de material, observa-se sua preocupação com alternativas para favorecer a compreensão do conteúdo pelos estudantes.

Uma maneira que P4 encontrou para fixar a informação na mente do aluno é a utilização das informações veiculadas na mídia, que estão fazendo sucesso com os jovens, por exemplo, alguma música que possa ser utilizada na contextualização dos conteúdos. Segundo o profissional, as aulas tornam-se mais descontraídas e envolventes e, além de prenderem a atenção, promovem a interação do grupo com o conteúdo.

Para fundamentar o que foi exposto por P4, utilizamos uma pesquisa realizada pela Universia Brasil (2011), a qual afirma que professores da Carolina do Norte, Estados Unidos, desenvolveram um modelo de formação chamado "Aprendizado Alternativo" para estudantes que apresentam baixo desempenho em sala de aula. Um dos modelos adotados consiste na Estratégia de Ativação, que visa estimular o estudante por meio de um determinado material apresentado, por exemplo, a utilização de vídeo e desenhos 
favoritos. Dessa forma, cria-se uma conexão entre estudante e objeto de estudo, facilitando a aprendizagem.

Diante do exposto, observa-se a necessidade de valorizar qualquer iniciativa dos docentes da escola pesquisada, pois os índices de evasão são altos, especialmente, no Ensino Médio.

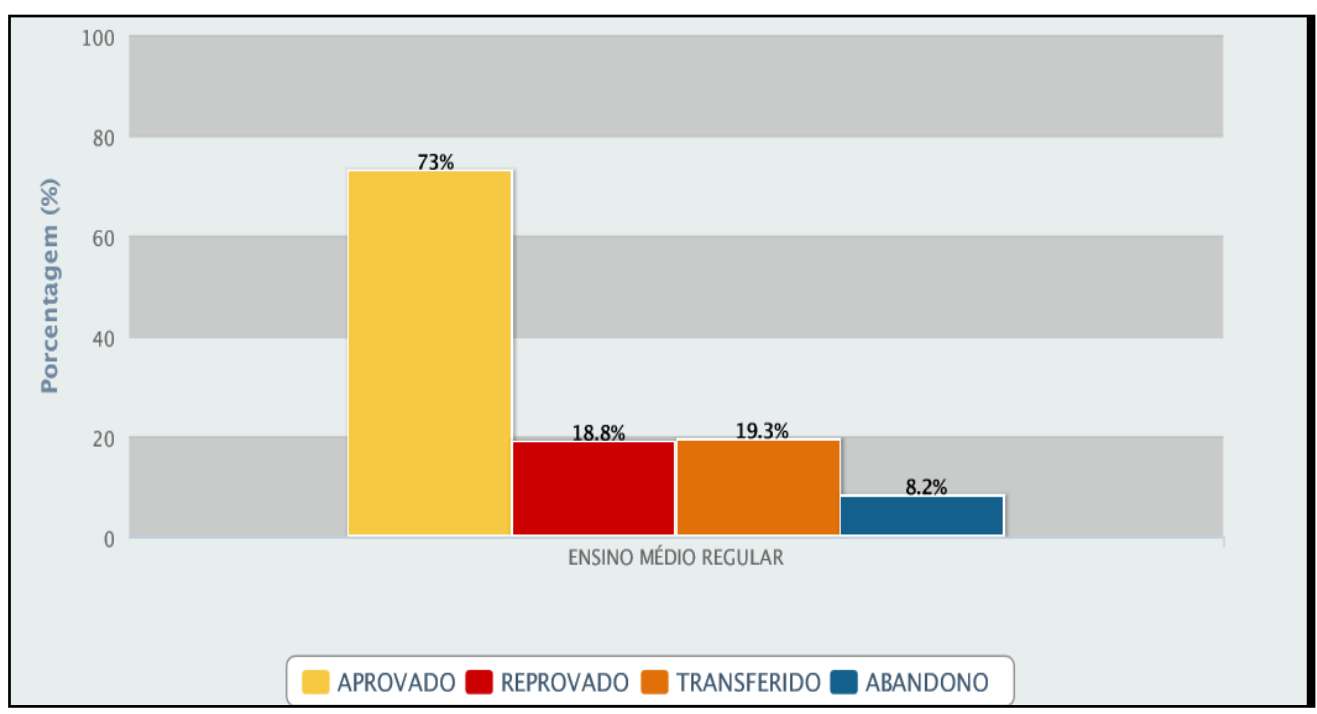

Figura 1. Índices de aproveitamento da escola pesquisada - ano 2010

Note: Fonte: MEC (2015)

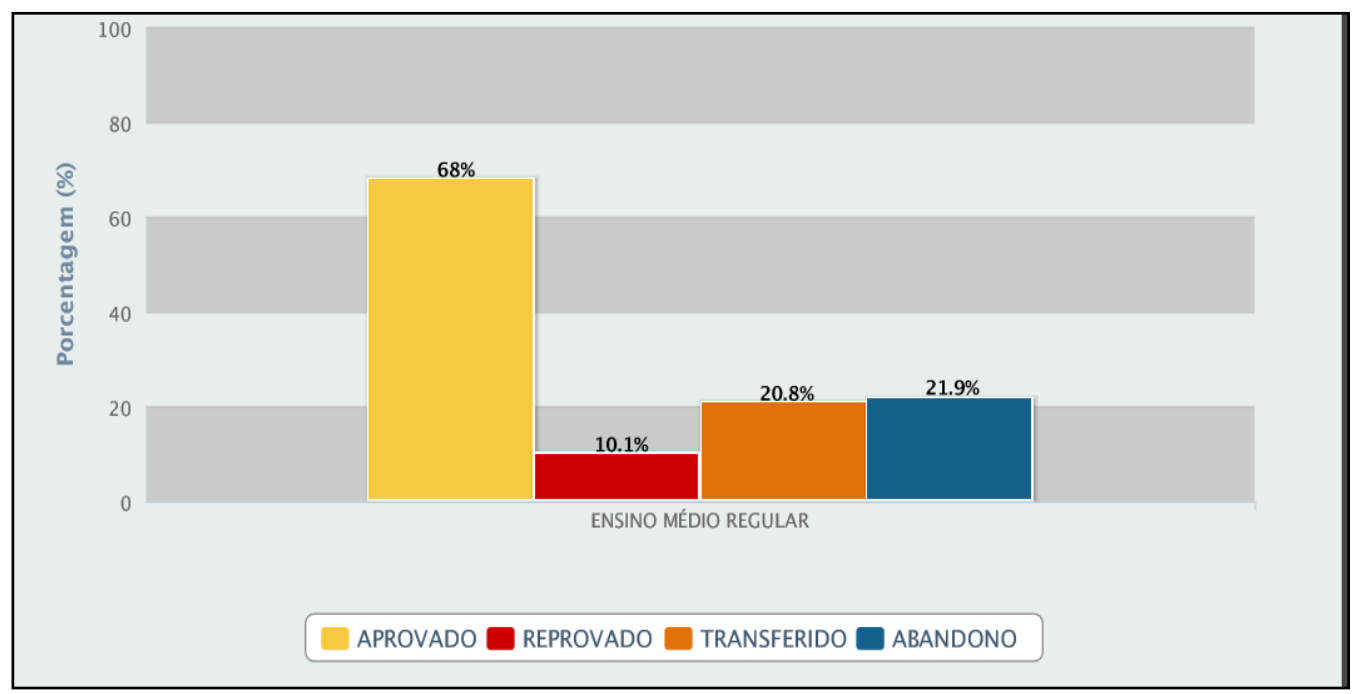

Figura 2. Índices de aproveitamento da escola pesquisada - ano 2010

Note: Fonte: Mec (2016)

Apesar das estratégias para a redução dos índices de evasão adotadas pela escola pesquisada, observa-se sua ampliação entre 2012 e 2015. Em conversas informais, os funcionários lembraram da falta de transporte para estudantes do período noturno, podendo ser um dos motivos que se reflete nos resultados. Outros fatores frequentemente 
citados foram: problemas de saúde, gravidez na adolescência, pais alcoólatras e, ainda, jovens assumindo responsabilidades que deveriam ser de seus pais,

\section{Conclusões}

Não há dúvida quanto à importância do professor no ambiente escolar, na medida em que ele mobiliza os processos de ensino e de aprendizagem. Todavia, nem sempre suas práticas são compatíveis com as necessidades dos estudantes e os estudantes não encontram sentido no que a escola se propõe a trabalhar.

Diante do que foi exposto pelos professores, ficou evidente que as metodologias utilizadas em sala de aula, em sua maioria, não estão de acordo com o que a coordenação da escola espera e, muito menos, com o que é estabelecido pelos PNC. O que se vê são professores desmotivados em função do desinteresse dos estudantes ou pela carga horária extensa e, até mesmo, por assumirem disciplinas que não são de sua área de formação. É evidente que fatores como esses contribuem para a disseminação de um ensino precário e fragmentado.

Mesmo diante destes fatores negativos, há professores que recorrem a metodologias diferentes, visando uma aula mais atrativa e envolvente. Estas práticas exitosas, como demonstram as pesquisas, vêm contribuindo para o desenvolvimento e a disseminação do aprendizado do aluno de forma significativa, estimulando a capacidade cognitiva dos mesmos e auxiliando em sua convivência.

\section{Referências}

Abed, A. L. Z. (2016). O desenvolvimento das habilidades socioemocionais como caminho para a aprendizagem e o sucesso escolar de alunos da educação básica. Revista Construção psicopedagógica, 24(25), 8-27. Recuperado em 22 de março de 2017, de http://pepsic.bvsalud.org/scielo.php?script=sci_arttext\&pid=S141569542016000100002\&lng=pt\&tlng=pt.

Alves, W. F. (2007). A formação de professores e as teorias do saber docente: contexto, dúvidas e desafios. Revista Educação e Pesquisa, 33(2), 2.

Araujo, J. C. S. (2006). Do quadro negro à lousa virtual: técnicas, tecnologia e tecnicismo. In: I. P. A. Veiga (Org.) Técnicas de ensino: Novos tempos, novas configurações. Campinas: Papirus.

Axt, R. e Moreira, M. A. (1991). O ensino experimental e a questão do equipamento de baixo custo. Revista Brasileira do Ensino de Física. 13, 97-103.

Bahia, J. (2001). A lei da vida: confirmação, evasão escolar e reinvenção da identidade entre os pomeranos. Educação e Pesquisa, 27(1), 69-82.

Barro, R. J. (1991). Economic Growth in a Cross Section of Countries. The Quarterly Journal of Economics, 106(2), 407-443.

Brasil (1988). Constituição da República Federativa do Brasil. Brasília: Senado. 
Brasil (1996). Diplomação, Retenção e Evasão nos Cursos de Graduação em Instituições de Ensino Superior Públicas. Brasília: ANDOFES/ABRUEM/SESu/MEC. Recuperado em 15 de maio de 2015, de http://www.andifes.org.br/wpcontent/files_flutter/Diplomacao_Retencao_Evasao_Graduacao_em_IES_Publica s-1996.pdf $>$.

Brasil (2000). Parâmetros Curriculares Nacionais - Ensino Médio. Brasília: MEC. Recuperado em 20 de março de 2016, de http://portal.mec.gov.br/seb/arquivos/pdf/blegais.pdf.

Bullough, R. V. (2015). Differences? Similarities? Male teacher, female teacher: An instrumental case study of teaching in a Head Start classroom. Teaching and Teacher Education, 47, 13-21.

Castillo, J. A. B. e Lopes, H. E. G. (1996). Avaliação do processo educacional num curso de Administração: o ponto de vista dos alunos. In: Atas do VII Encontro Nacional dos Cursos de Graduação em Administração. Florianópolis: Angrag.

Cerati, T. M. (2014). Educação em jardins botânicos na perspectiva da alfabetização científica: análise de uma exposição e público. Tese de Doutorado. Faculdade de Educação da Universidade de São Paulo, São Paulo.

Cooke, S. e Carr, D. (2014). Virtue, Practical Wisdom and Character in Teaching. British Journal of Educational Studies, 62(2), 91-110.

Dore, R. e Luscher, A. Z. (2001). Permanência e evasão na educação técnica de nível médio em Minas Gerais. Cadernos de Pesquisa, 41(144), 770-789.

Enguita, M. F. Educar em tempos incertos. Porto Alegre: Artmed, 2004.

Ferreira, A. B. H. (2009). Novo Dicionário Aurélio eletrônico - versão 6.0. 4ª ed. Curitiba: Positivo.

Fundação Victor Civita (2011). Formação Continuada de Professores: Uma análise das Modalidades e das Práticas em Estados e Municípios Brasileiros. Fundação Carlos Chagas. Recuperado em 01 de abril de 2016, de http://www.fvc.org.br/pdf/relatorio-formacao-continuada.pdf.

Gadotti, M. Histórias das ideias pedagógicas. São Paulo: Ática, 1995.

Giddens, A. Sociologia. Porto Alegre: Artmed, 2005.

Guskey, T., e Huberman, M. (1995). Professional Development in Education: New Paradigms and Practices. New York: Teachers College.

Instituto Universia Brasil (2011). Dez dicas para envolver alunos com baixo empenho. São Paulo: IUB Recuperado em 02 de abril de 2016, de http://noticias.universia.com.br/destaque/noticia/2011/12/06/895933/10-dicasenvolver-alunos-com-baixo-desempenho.html. 
Lamers, J. M. S., Santos, B. S. e Toassi, R. F. C. (2017). Retenção e evasão no ensino superior público: estudo de caso em um curso noturno de Odontologia. Educação em Revista, 33, 1-28.

Libâneo, J. C. (2001). O essencial da didática e o trabalho de professor - em busca de novos caminhos. Recuperado em 08 de maio de 2016, de http://www.ucg.br/site_docente/edu/libaneo/pdf/didaticadoprof.pdf,

Lucas Jr., R. E. (1988). On the mechanics of economic development. Journal of Monetary Economics 22, 3-42.

Mankiw, N. G., Romer, D. e Weil, D. N. (1992). A Contribution to the Empirics of Economic Growth. The Quarterly Journal of Economics, 107 (2), 407-437.

Mec (2015). Taxas de rendimento. Brasília: Ministério da Educação - MEC.

Murnane, R. J., Willett, J. B. e Levy, F. (1995). The Growing Importance of Cognitive Skills in Wage Determination. The Review of Economics and Statistics, 77(2), 51266.

Nóvoa, A. (1992). Os Professores e a sua formação. Lisboa: Instituto de Inovação Educacional.

Nóvoa, A. (1999). Os professores na virada do milênio: do excesso dos discursos à pobreza das práticas. Revista Educação e Pesquisa, 25(1), 11-20.

Pedralli, R. e Cerutti-Rizzatti, M. E. (2013). Evasão escolar na educação de jovens e adultos: problematizando o fenômeno com enfoque na cultura escrita. Revista Brasileira de Linguística Aplicada, 13(3), 771-788.

Perrenoud, P. (2000). Construir competências é virar as costas aos saberes? Revista Pátio, 3(11), 15-19.

Saviani, D. (2000). Pedagogia histórico-crítica: primeiras aproximações. $7^{\mathrm{a}}$. ed. Campinas: Autores Associados.

Saviani, D. (2009). Formação de Professores: aspectos históricos e teóricos do problema no contexto brasileiro. Revista brasileira de educação, 14(40), 143-155.

Silva Filho, R. L. e outros (2007). A evasão no ensino superior brasileiro. Cadernos de Pesquisa, 37(132), 641-659.

Silva, E. R. e Abud, M. J. M. (2016). As representações docentes sobre as causas da indisciplina na escola: de quem é a culpa? Revista do GEL, 13(1), 87-106.

Souza, S. A. e Reinert, J. N. (2010). Avaliação de um curso de ensino superior através da satisfação/insatisfação discente. Avaliação: Revista da Avaliação da Educação Superior, 15(1), 159-176.

Torrance, D. (2015). Professional learning for distributed leadership: primary head teachers' perspectives. Professional Development in Education. 41(3), 487-507. 
Tuxford, L. e Bradley, G. (2014). Emotional Job Demands and Emotional Exhaustion. Teachers. Educational Psychology, 1-19.

Tuxford, L. M. e Bradley, G. L. (2014). Emotional job demands and emotional exhaustion in teachers. Educational Psychology, 66, 1-19.

Veiga, I. P. A. e outros (2000). Pedagogia universitária: a aula em foco. São Paulo: Papirus.

Wang, H.; Hall, N.C. e Rahimi, S. (2015). Self-efficacy and casual attribution in teachers: Effects on burnout, job satisfaction, illness and quitting intentions. Teaching and Teacher Education, 47, 120-130.

Data de recebimento: $23 / 03 / 2017$

Data da revisão: 05/05/2017

Data do aceite: $24 / 06 / 2017$ 
